\title{
Sentencing the Multiple Offender
}

\author{
In Search of a "Just and Proportionate" Total Sentence
}

ANDREW ASHWORTH AND MARTIN WASIK

The multiple offender will receive a shorter (perhaps much shorter) sentence if she or he is dealt with for several offenses on a single sentencing occasion than if sentenced for those same offenses on two or more separate sentencing occasions. This is the "discount for bulk offending," a practice which is widely adopted in different sentencing systems but which is hard to justify theoretically, either in retributive or deterrent terms. In this chapter we focus on custodial sentences, where the issues are at their most stark.

In England, the jurisdiction with which we are mainly concerned in this chapter, the tools for determining custodial sentences in the case of multiple offenders are threefold: concurrent sentences, consecutive sentences, and the totality principle. Custodial sentences imposed on the same sentencing occasion in England cannot overlap. This means that the total sentence must always be arrived at through a combination of concurrent and/or consecutive sentences.

We begin the chapter by attempting to identify the rationale of the totality principle, examining how it operates and seeking a justification for the principle. We then turn to scrutinize the component parts of the totality principle, examining six problematic issues. We then develop our argument that totality should be regarded as the determining principle when sentencing for multiple offenses, discussing the approach of some other jurisdictions before formulating what we regard as necessary changes in the sentencing guidelines for England and Wales.

\section{Identifying the Rationale of the Totality Principle}

The totality principle applies to all multiple-offense cases, whatever combination of concurrent or consecutive sentences a particular judge adopts. Whether 
sentences are imposed concurrently, or consecutively, or in a mix, the total sentence should, in principle, be unaffected. The practical operation of this principle can clearly be seen in many English appellate decisions. If the Court of Appeal finds that the judge has achieved totality in his or her sentence then only rarely will the Court quibble about the particular combination of concurrent and / or consecutive sentences which were employed by the judge to reach that result. The overriding requirement when sentencing multiple offenders is that the judge has reflected totality - an appropriate overall custodial sentence.

Three questions need to be addressed in connection with the central concept of totality. First, how does the totality principle operate? Secondly, what is the rationale for the principle? And thirdly, what are its component elements?

First, the operation of the totality principle (in outline). Everyone agrees that in the case of a multiple offender the total sentence should be greater than the proportionate sentence for any one of the offenses. This is true whether the judge employs consecutive or concurrent sentences, or a mixture of both, to achieve the final outcome. The totality principle, however, operates to restrict the sentence that might otherwise result from adding together the single sentences for each of the offenses. This restrictive principle applies so as to reduce the sentence for someone who has committed several offenses, whether these were committed close together in time or over a considerable period.

This prompts the question (posed forcefully by Reitz, 2010, p. 138) of why the multiple offender's sentence is restricted when the repeat offender who is caught and sentenced on each separate occasion receives enhanced sentences (not restricted sentences) on account of the persistence of the offending. Before confronting that question, two preliminary points must be noted. First, one should beware of exaggerating the difference between those two sentencing approaches. Desert theory does allow modest increases in sentence for persistent offenders, subject to a "ceiling" reached after three or four offenses, after which there should be no further increases (an approach clearly reflected in Crown Court sentencing practice; see Roberts and Pina-Sanchez, 2014). Multiple offenders do receive an incremental increase for each subsequent offense, although the size of the increment diminishes as the number of offenses rises. Empirical evidence is lacking here, but the rarity with which Crown Court judges exceed the "offense range" set out in sentencing guidelines strongly suggests that sentences passed for multiple offenses do generally fall within the same broad parameters as sentences passed for a single offense. However, that said, the difference in approach remains considerable, and the responses to both multiple offenders (sentenced "simultaneously," as Frase 2013, ch. 4, puts it) and persistent offenders (sentenced "sequentially") ideally ought to be incorporated into a single and consistent matrix. 


\section{Justifying the Principle}

The second preliminary point is that the presence of multiple offenses and the presence of previous offenses on the offender's record are each taken into account at two stages of reasoning. At the first stage the presence of the other offenses requires that the total sentence imposed on the present occasion is always higher than it otherwise would be. A serious prior criminal record, the presence of other offenses for which the offender is being sentenced at the same time (and "offenses taken into consideration," for that matter), ${ }^{1}$ all serve to increase the seriousness of the case. At the second stage, however, the total sentence is scaled back so as to set a limit upon the effect which the presence of multiple offenses or offenses on the offender's record would otherwise have. We argue that the previous convictions of the offender with a serious record, and the "non-lead offenses" of a multiple offender, simply provide part of the context within which the assessment of offense seriousness can fairly be made.

How can the rationale for the totality principle be explained? Three possible explanations can be considered. First, it might be argued that the multiple offender who is sentenced on one occasion for several offenses differs from other persistent offenders because the latter have had authoritative warnings (in the shape of convictions and sentences) which the multiple offender has not received, and indeed may have served sentences that have a criminogenic (rather than a rehabilitative) effect. This is certainly a distinction between the two classes of offender, but it is not clear that the difference is weighty enough to justify the different approaches to sentencing, not least because there is usually no question that the multiple offenders knew they were committing offenses and were, at that stage, avoiding detection.

Secondly, it is sometimes argued that the basis for the restrictive effect of the totality principle lies in the direction of mercy, the principle of parsimony or restraint, or even the right to human dignity. These are indeed important principles, but it is not clear why they should apply to multiple offenders rather than to any offender who is likely to receive a substantial custodial sentence. All such sentences are hard, and are likely to have a "crushing effect" on many of those subjected to them. However, it is fair to note that one of the problems of consecutive sentencing (especially if it operates in an unbridled way) is that it may result in a total punishment of years amounting to much of the offender's remaining life-time or even (illogically) running well beyond that period. Consecutive sentences rapidly become nonsensical, particularly with elderly offenders being sentenced for multiple historic offenses. In principle - and this is supported by the right to human dignity - the total sentence imposed on an offender should always be one which is capable of being served within the offender's lifetime 
(subject to the whole-life minimum term issue, considered in Vinter v. UK [2013] and Hutchinson v. UK [2015]).

Thirdly, and notwithstanding the fact that the two arguments seem less than compelling, it appears that a majority of members of the public support some kind of totality principle (see Robinson and Darley, 1995, p. 193; Roberts, 2008, pp. 180-182), and that intuitively interoffense proportionality is the dominant consideration. In other words, several lesser offenses should not combine to produce a sentence above that which is appropriate for a significantly more serious offense. Thus, while part of the thrust of this rationale is that it is based on public opinion, its deeper roots lie in the intuitive attraction of a version of proportionality theory that privileges interoffense proportionality above intraoffense proportionality. In other words, the primary determinant of proportionality here is the most serious of the offenses for which sentence is being passed, rather than the sheer number of lesser offenses. There is some philosophical support for the "strong intuitive basis" for the reduction in multiple-offense sentencing (see Bennett, 2012, p. 138). We would concede that there may be combinations of facts that challenge the intuitive attraction of interoffense proportionality (see Reitz, 2010, p. 146), but in many cases the primacy of interoffense proportionality is a reasonable starting-point.

\section{What Are the Component Parts of the Totality Principle?}

Without concluding our tentative discussion of rationales, it is now appropriate to examine the component elements of the totality principle. A major element is the proposition that it is inappropriate to sentence the multiple offender simply by doing the arithmetic and adding together the sentences for the individual offenses. The Sentencing Council moves from this proposition to the repeated assertion that the sentence must be "just and proportionate," without further elaboration (Sentencing Council, 2012, criticized by Ashworth, 2015, pp. 282286). This formulation should be rejected on the ground that it ducks the issues and leaves relatively unbridled judicial discretion. While (as we elaborate in the next section) a major purpose of multiple-offense sentencing should be to achieve proper presentation and communication, the notion of totality is dependent on the resolution of some tough normative questions.

What goes into judgments of totality? For example, is there not a significant difference between three or four offenses arising out of the same incident, and three or four offenses committed over a period of time? In calculating totality there must surely be a difference between these two types of core case; although it is true that (a) there are some contestable cases where the idea of a single 
incident is stretched as a concept (for examples, see Wasik, 2012, pp. 294-297) and (b) there is at least a presentational argument for a different approach where, for example, different legal prohibitions have been violated in the incident. This is not about consecutive or concurrent sentences; it is about the elements that go to make up totality, ensuring that there is no undercounting or double-counting. Similarly, when calculating totality, should it matter whether several offenses were committed against the same victim or against different victims?

These are among the questions we need to answer, in order to unpack the notion of a just and proportionate overall sentence. In the following section we set out six possible aspects of the relationship between the offenses to be sentenced, that may affect the quantum of the total sentence-factors that tend to move the total sentence upward or downward:

1) The genuine single incident (the nonproblematic cases); such as the robbery with a carried weapon or the burglary with a weapon. In principle, if there are two charges (robbery, carrying an offensive weapon) the sentence should be the same as it would be if only robbery were charged and the carrying of the weapon were treated as a factor aggravating the robbery. It can fairly be regarded as a single incident or single transaction. Thus, if a person were charged with a robbery last week and carrying an offensive weapon this week, these two offenses cannot be seen as a single incident and one might therefore expect the total sentence to be higher than in the "single incident/ transaction" case. However, as one of us has argued before (Wasik, 2012), the boundaries are often blurred and so there are limits to the usefulness of the "single incident" concept. Thus, consider a case where D commits a house burglary to take the car keys, steals the high performance car belonging to the householder, and then drives it dangerously, ultimately resulting in a police chase and D's arrest. These three offenses are certainly linked together (in time and context), but it is not very helpful to ask whether this is one incident or two or three. In order to achieve totality one would expect there to be some aggregation of the sentences for the burglary, the theft and the dangerous driving.

2) Where there is a series of similar offenses over a period of time, the best approach is to aggregate the offenses and to sentence as if it is a composite offense. This is straightforward where there is a series of benefit frauds, or thefts from an employer, where it is possible to aggregate the loss/gain into a single total. Where there is a series of similar sexual or physical abuse cases over time, this aggregative approach may still be adopted in principle, but the detailed approach is likely to be different. Several offenses of assault occasioning bodily harm could be cumulated by adding the sentences together, and the same for a series of sexual offenses; but whereas the approach to repeated 
property offenses is to produce a figure for total gain/loss, the approach to other offenses is to aggregate the individual sentences. This would clearly engage the restrictive element of the totality principle; but should not the aggregation of gain/loss in property offenses also engage the totality principle?

3) Where the series of offenses is committed against the same victim, is this more or less serious than the same offenses against different victims? The Sentencing Council seems to say different things, by suggesting that repetitive thefts from the same person should usually attract concurrent sentences whereas repetitive offenses of domestic violence or sexual offense against the same person should attract consecutive sentences (Sentencing Council, 2012, pp. 6-7). Admittedly these remarks do not relate to the totality principle directly, but there is a strong implication in the Council's discussion that the totality principle may exert a more restrictive effect when property offenses are committed against the same person than when sexual offenses or domestic abuse are committed. There seems to be no good reason to distinguish between repeated victimization of the same person and of different persons, unless there is evidence that a vulnerable person was targeted-an independent aggravating factor.

4) If one or more of the offenses are committed while on bail for another offense being sentenced on the same occasion, this should raise the total sentence by a significant amount. ${ }^{2}$ Two reasons for this are that (a) the new offense is clearly separated in time from the original offense, and (b) offending on bail violates a separate interest, in the sense that an important element of trust is breached by the commission of offenses while awaiting a court hearing on other charges.

5) If one or more of the offenses involve assault on the police, for example to try to escape arrest in relation to another offense being sentenced on the same occasion, this should raise the sentence by a significant amount. Two reasons for this are that (a) the new offense is likely to violate a separate interest (unless the original offense was also an attack on the police), and (b) this separate interest is one that requires extra protection, since police officers are required to place themselves in vulnerable positions in order to carry out their public duties.

6) If one of the offenses is an offense against the administration of justice committed in relation to another offense being sentenced, this should raise the sentence by a significant amount. This is along similar lines to point (4), but it relates to offenses such as perverting the course of justice, as by trying to conceal evidence or to claim that the offense was committed by another or to bribe a witness to keep quiet. The main rationales for this would, again, be that the offense violates a separate and socially important interest.

These six factors are relevant to determining whether the total sentence should be adjusted upward or downward, and therefore to the principle that the sentence 
of the multiple offender should attempt to reflect the offending behavior as a whole. Where should the court start in its assessment of totality? Other jurisdictions have tackled this problem by developing formulae to guide sentencers in arriving at totality in multiple-offense cases. In Germany, for example, the traditional model has been to give full penal weight to the most serious offense to be sentenced and then to add to that figure roughly half of the total penal weight attaching to the sum of all the other offenses. An account of this is provided by Jareborg (1998, pp. 135-137), describing the work of Hans-Jorg Albrecht and Joachim Bohnert. A more elaborate model has been developed in Sweden, whereby full penal weight is given to the most serious offense, to which is added half of the penal weight for the second most serious offense, one third of the penal weight for the third most serious offense, and so on. The model, as developed by Borgeke, a Swedish Appeal Court judge, is considered in more detail by Vibla (2013, pp. 86-88). In Vibla's interviews with Swedish judges (pp. 89-104) she found a broad acceptance of Borgeke's approach as a way to achieve greater consistency in multiple-offense cases, provided that the formula was applied flexibly. This approach certainly has something to recommend it, but the relationship between the mathematical models and the six factors identified earlier needs to be more clearly elaborated. The discussion suggests that interoffense proportionality is the key guide, taking the lead offense as a pointer but adding incrementally to reflect the other offenses.

From this discussion of the factors that may determine the assessment of the total sentence, we now move on to the presentational issue of concurrent/ consecutive sentences. There would be some difficulty in accommodating the German/Swedish approach to multiple-offense sentencing within the English tradition of concurrent/consecutive sentencing. In English sentencing practice the position is that all the offenses in a multiple-offense case must receive their proportionate sentence, but that some or all of those sentences will be ordered to run concurrently rather than consecutively, to comply with totality. The sentence imposed for each offense will appear on the offender's criminal record. In the German-Swedish model the sentences for all individual offenses other than the lead offense are artificially shortened to achieve totality. It is simply the global sentence which then appears on the offender's record.

\section{Presentation, Communication, and the Totality Principle}

We take the view that totality is the determining principle when sentencing multiple offenders, rather than just a limiting principle (as Thomas, 1979, pp. 56-61 argued, and as reflected in Sentencing Council guidelines). If we are right that 
totality is the determining principle, then, if a judge chooses to deal with one of the offenses by way of a consecutive sentence, there must be some adjustment to sentences for other offenses in order to retain totality. The selection of concurrent and consecutive sentences within totality is, for the most part, a matter of presentation of the total sentence (to the defendant, the victim, and the wider public). There is no proportionality issue in the choice between concurrent and consecutive sentences. Of course presentation is important for communicative reasons, and can be particularly so in sensitive cases, such as those involving multiple deaths (see the examples in Wasik, 2012, pp. 299-301). While it is possible to imagine the English sentencing system operating without consecutive sentences at all, the importance of presentation in some cases means that there is value in their occasional use. There should, however, be a clear presumption in favor of concurrent sentences.

The most straightforward case, perhaps, is one where there is a clear lead offense in terms of seriousness, and then one or more lesser offenses. The principle is to pass a somewhat enhanced sentence for the lead offense (enhanced by treating the other offenses as aggravating the lead offense) and then to use concurrent sentences for the rest. This principle certainly applies both at the lower end of the custodial sentencing scale (for example, dangerous driving, plus no tax, no insurance) and at the higher end. For example, in Pinnell (2011) the Court of Appeal said that where an extended sentence is to be imposed on a multiple offender all the offenses should be looked at in the round before imposing the extended sentence for the most serious matter and passing concurrent sentences for the rest. Then there is the case of several offenses (say, assault) committed against the same victim, or against different victims. Generally, this is better dealt with by concurrent rather than consecutive sentences because (especially if there are more than two offenses) using consecutive terms means that some or all of the assaults have to be undersentenced to keep within totality. Concurrent sentences allow the judge to pass a proportionate sentence for each assault.

The most difficult case is where the offender falls to be sentenced for two entirely unrelated matters (burglary committed on one occasion and assault on another). Some would prefer consecutive sentences here, but that approach requires each sentence to be shorter than it would be if standing alone. Concurrence allows the judge to pass appropriate sentences for each matter, and thereby to impose a proportionate overall sentence. If, as sometimes happens, the defendant faces charges on two separate but unrelated indictments, the best approach may be to select the lead offenses from each of the two indictments, pass consecutive sentences for those and concurrent sentences for all the rest.

In the context of the sentencing guidelines for England and Wales, our arguments in this chapter point to the need for two major changes - the first relating to the standard contents of the offense guidelines, and the second relating to the generic guideline for sentencing multiple offenders. 


\section{Offense Guidelines}

On the first point, we think that the totality principle should be more clearly incorporated into offense guidelines, which have hitherto focused on single offenses and have largely ignored the complexities of multiple offending. Given the frequency with which multiple offenses are sentenced, and the determining role of totality, it is not appropriate to relegate totality to step 6 of the Sentencing Council's guidelines, as it currently is. ${ }^{3}$ In addition to step 6 (which we think should be retained as a useful check), more detailed guidance should be given earlier, at step 2 (starting point and category range). Guidelines at step 2 set out a table of "factors increasing seriousness" and "factors reducing seriousness or reflecting personal mitigation," and typically contain the following wording (e.g., guideline on Assault, 2011):

The table ... contains a non-exhaustive list of additional factual elements providing the context of the offence and factors relating to the offender. Identify whether any combination of these, or other relevant factors, should result in an upward or downward adjustment from the starting point. In some cases, having considered these factors, it may be appropriate to move outside the identified category range.

The table does not cater for multiple offenses, and indeed there is no mention of the issue at all. In something of a change of direction, a recently published offense guideline (on Theft Offences, 2016) contains the following additional statement at step 2:

The table ... refers to single offences. Where there are multiple offences consecutive sentences may be appropriate: please refer to the Offences Taken into Consideration and Totality guideline.

This wording appears in relation to some of the particular offenses covered (general theft, theft from a shop, handling stolen goods, and going equipped for theft), but not others (abstracting electricity and making off without payment). It seems clear from the context that the reference in the guideline to multiple offenses is meant to be limited to multiple instances of the same particular offense, and not to sentencing multiple offenses more generally. ${ }^{4}$

We think that more assistance should be provided, and suggest that the following should be incorporated at step 2 of each offense guideline:

If sentencing the offender for more than one offence:

(i) There is a presumption in favor of passing concurrent sentences for all offences being dealt with, but in some cases consecutive sentences may 
be appropriate: please refer to the Offences Taken into Consideration and Totality guideline.

(ii) It will normally be appropriate to pass a total sentence which is within the category range appropriate to the most serious of the offences, although the presence of one or more other offences (whether similar to or different from the most serious offence) will normally require the adoption of a higher starting point than would be appropriate for a single offence. In some cases, having considered these factors it may be appropriate to move outside the identified category range.

And, in the table column "Factors Increasing Seriousness: Other Aggravating Factors Include" the following additional wording should appear:

Offender being sentenced for more than one offence.

\section{English Guideline on Totality}

Moving to the second major change that is necessary, we would recommend reconsideration of the Sentencing Council's guideline on Offences taken into Consideration and Totality (2012), so as to make it clear that the totality principle is a determining principle that should form an important part of the court's reasoning from step 2 onward in all multiple-offense cases, rather than simply a late-stage check at step 6 to see whether the sentence intuitively seems too high. There are some features of the totality guideline with which we agree. We agree that when sentencing a multiple offender the court "should pass a total sentence which reflects all the offending behaviour... whether the sentences are constructed as concurrent or consecutive," and that "there is no inflexible rule governing whether sentences should be ... concurrent or consecutive."

We disagree, however, with the Sentencing Council's general approach that the court should "consider the sentence for each individual offence," then "determine whether the case calls for concurrent or consecutive sentences," and then "test the overall sentence(s) against the requirement that they be just and proportionate." At present the guideline usefully summarizes the earlier case-law on the use of concurrent and consecutive sentences, but actually says nothing about the proper role of the totality principle, and gives no clues as to how the court should assess totality in any particular case. What appears at step 6 in the offense guidelines under totality principle is:

If sentencing an offender for more than one offence... consider whether the total sentence is just and proportionate to the offending behaviour. 
Neither this statement, nor the totality guideline as a whole, assists a judge in selecting the just and proportionate sentence for all the offending behavior. So, what additional ground should a revised totality guideline cover?

We said earlier that the most straightforward multiple offense case is one where there is a clear lead offense in terms of seriousness, and then one or more lesser offenses. We think that the advice should be for the judge to move at step 1 to the category range appropriate for the lead offense. The judge should always explain his or her conclusion on step 1 before moving to step 2, as required by the decision in Attorney-General's References (Nos 15, 16 and 17 of 2012) (2013). Almost inevitably, the presence of multiple offenses will justify a move upward within the category range. There will be some cases where the presence of multiple offenses (taken together with all other factors) will require the court to move up from one category range to the next. Moving from one category range to another is not a departure from the offense guideline, but it was said in Datsun (2014) that it was always desirable for the judge to explain why this has occurred. Very occasionally the presence of multiple offenses (taken together with all other factors) may justify a provisional sentence at the end of step 2 (prior to any reduction for a guilty plea, etc.) which is above the top of the offense range. To arrive at a sentence above the top of the offense range is a departure from the offense guideline and would require the judge to explain that to pass a sentence within the offense range would be contrary to the interests of justice (Coroners and Justice Act, 2009, s.125(1)).

Pausing there, it is worth noting in more detail the empirical evidence which shows that in practice in the Crown Court upward departures from offense guidelines are very rare (Sentencing Council, 2014). In 2014 they occurred in $2 \%$ of cases involving assault occasioning actual bodily harm, $3 \%$ of cases of domestic burglary, and $0.5 \%$ of cases of cultivation of cannabis. These figures strongly suggest that in the great majority of cases the upper category range in the offense guidelines is perfectly adequate to deal with the worst multiple-offense cases. Ordinarily in the offense guidelines there is a significant gap between the top of the offense range and the maximum penalty for the offense to cater for cases where the court does need to depart from the guideline. For assault occasioning actual bodily harm the top of the offense range is three years but the maximum is five years. For domestic burglary the top of the offense range is six years but the maximum is 14 years. For cultivation of cannabis the top of the offense range is 10 years but the maximum is 14 years. In very rare cases aggravating factors, including the presence of multiple offenses, may justify the passing of a final sentence which is higher than the maximum penalty for any one of the offenses being sentenced. Sentencing in excess of the maximum can only be achieved by the use of consecutive sentences. The recent offense guideline on general theft 
(theft carries a maximum penalty of seven years) recognizes that, and contains the following statement at step 2:

Where multiple offences are committed in circumstances which justify consecutive sentences and the total amount stolen is in excess of $£ 1$ million, then an aggregate sentence in excess of seven years may be appropriate.

This is the first time that such a statement has appeared in an offense guideline, ${ }^{5}$ and there is no explanation given in the text for singling out the offense of theft in this way. It could be taken as confirmation that the Crown Court should not normally use consecutive sentences to exceed the maximum. As we have seen, the maximum for assault occasioning actual bodily harm is five years, so the inference is that no matter how many instances of that offense are being sentenced on the same occasion the sentence should never exceed five years before adjustment for guilty plea and any other matters. Relatively technical these issues may be, but they ought to be resolved if the sentencing guidelines system is to cater properly for the sentencing of multiple offenses.

\section{Conclusion}

In this chapter we have sought to confront some of the difficult practical issues that arise in multiple-offense sentencing, and to place them in the context of the strongest justification for the totality principle. Our argument is that totality should be regarded as the determining principle when sentencing multiple offenders, rather than simply as a limiting principle. We also argue that the choice between concurrent and consecutive sentencing should be seen as a presentational and communicative issue, and we make concrete proposals about ways in which the totality principle should be reformulated in the generic guidelines on totality, and more clearly incorporated into the various offense guidelines issued by the Sentencing Council for England and Wales.

\section{Notes}

1. The English practice of taking offenses into consideration means that an offender who is about to be sentenced can ask the court to take account of other offenses that he admits to committing but with which he has not been charged. In practice, this usually happens in relation to offenses similar to the type for which he is already being sentenced, and the effect will be to increase the overall sentence (see further Ashworth, 2015, p. 275).

2. One cannot prescribe what the incremental increase would be, but it should be a just noticeable difference in order to signify the violation of this separate interest. 
3. Some explanation is necessary for those unfamiliar with the structure of the English sentencing guidelines. Each guideline relates to one offense or one group of offenses. The court is usually required to go through 8 or 9 steps in order to impose the appropriate sentence and orders. In brief, step 1 sets out the harm and culpability factors on the basis of which the court should determine which offense category the offense falls. Step 2 sets out a number of aggravating and mitigating factors that the court may use in order to determine whether to move upward or downward from the starting point in the appropriate offense category. Step 3 concerns further reductions for assistance to the prosecution; step 4 requires the court to reduce sentence to reflect a plea of guilty; step 5 (where applicable) requires the court to have regard to the criteria for sentencing dangerous offenders; step 6 is the totality principle; step 7 requires the court to consider ancillary orders; step 8 requires the court to formulate its reasons; and step 9 requires the court to adjust the sentence accordingly if the defendant was subject to a qualifying curfew while remanded on bail.

4. The new wording does not appear in relation to abstracting electricity. It is perhaps unlikely that a defendant would fall to be sentenced for multiple instances of that offense, but abstracting electricity is commonly encountered as an offense associated with other offenses, especially production of cannabis.

5. Nor does it appear in relation to the other offenses covered in the Theft Offences guideline, such as theft from a shop or handling stolen goods.

\section{References}

Ashworth, A. 2015. Sentencing and Criminal Justice. 6th ed. Cambridge: Cambridge University Press.

Bennett, C. 2012. "Do Multiple and Repeat Offenders Pose a Problem for Retributive Sentencing

Theory?” In C. Tamburrini and J. Ryberg (eds.), Recidivist Punishments: The Philosopher's View, pp. 137-156. Lanham, MD: Lexington Books.

Frase, R. S. 2013. Just Sentencing: Principles and Procedures for a Workable System. New York: Oxford University Press.

Jareborg, N. 1998. "Why Bulk Discounts in Multiple Offence Sentencing?” In A. Ashworth and M.

Wasik (eds.), Fundamentals of Sentencing Theory: Essays in Honour of Andrew von Hirsch, pp. 129-140. Oxford: Clarendon Press.

Reitz, K. 2010. “The Illusion of Proportionality: Desert and Repeat Offenders.” In J. V. Roberts and A. von Hirsch (eds.), Previous Convictions at Sentencing: Theoretical and Applied Perspectives, pp. 137-160. Oxford: Hart Publishing.

Roberts, J. V. 2008. Punishing Persistent Offenders: Exploring Community and Offender Perspectives. Oxford: Oxford University Press.

Roberts, J. V., and J. Pina-Sanchez. 2014. "Previous Convictions at Sentencing: Exploring Empirical Trends in the Crown Court." Criminal Law Review: 575-588.

Robinson, P., and J. Darley. 1995. Justice, Liability and Blame: Community Views and the Criminal Law. Boulder, CO: Westview Press.

Sentencing Council for England and Wales. 2011. Definitive Guideline: Assault.London: Sentencing Council for England and Wales.

Sentencing Council for England and Wales. 2012. Offences Taken into Consideration and Totality: Definitive Guideline. London: Sentencing Council for England and Wales.

Sentencing Council for England and Wales. 2014. Crown Court Sentencing Survey Annual Publication (January to December 2014). London: Sentencing Council for England and Wales.

Sentencing Council for England and Wales. 2016. Definitive Guideline: Theft Offences. London: Sentencing Council for England and Wales.

Thomas, D. A. 1979. Principles of Sentencing: The Sentencing Policy of the Court of Appeal Criminal Division. 2nd ed. London: Heinemann.

Vibla, N. 2013. "Sentencing for Multiple Offences: Towards a Conceptual Model within a Retributive Framework." Unpublished $\mathrm{PhD}$ thesis, University of Cambridge. 
Wasik, M. 2012. "Concurrent and Consecutive Sentences Revisited." In L. Zedner and J.V. Roberts (eds.), Principles and Values in Criminal Law and Criminal Justice: Essays in Honour of Andrew Ashworth, pp. 285-306. Oxford: Oxford University Press.

\section{CASE LAW}

Attorney-General's References (Nos 15, 16 and 17 of 2012) [2013] 1 Cr App R (S) 52 Datsun [2014] 1 Cr App R (S) 25

Hutchinson v. United Kingdom (2015) 61 EHRR 393

Pinnell [2011] 2 Cr App R (S) 168

Vinter v. United Kingdom [2013] ECHR 645

\section{LEG ISLATION}

Coroners and Justice Act 2009, UK 